\title{
Health problems experienced by parents of children in long-term hospital stay
}

\author{
Maria de Lurdes Lopes de Freitas Lomba', Inês Abreu², Rafaela Oliveira², \\ Rodrigo Rato2, Rúben Pinto ${ }^{2}$, M. Sofia Macedo ${ }^{3}$ \\ I Health Sciences Research Unit: Nursing. Coimbra Nursing School Nursing, Portugal. \\ ${ }^{2}$ Coimbra Nursing School Nursing. Portugal. \\ ${ }^{3}$ Saudi Patient Safety center, Saudi Arabia
}

\begin{abstract}
Introduction: Nowadays, parental active engagement in children' hospitalization has become an accepted feature. However, parental finance, social and personal costs for their involvement in their child's care have received little attention. Moreover, a child's hospitalization is, frequently, an event that occurs, unexpectedly, having a significative impact on parents' health. There is a positive relationship between parental anxiety and the length of the child's hospital admission. Aim: To synthesize and analyse the existing evidence on the health problems experienced by parents of children in a long-term hospital stay. Method: An integrative review was carried out, and scientific articles were selected from the databases MEDLINE, SciELO and CINAHL. Only parents of children (with ages between o and 18 years) submitted to longterm hospitalizations were included. Parents with any kind of mental or psychiatric disorder were excluded from the review. A six-step method was used to develop the revision and to analyse the results. Results: A child's hospital stay holds major changes in the routines and well-being of a family. Parents are in need of care from nurses whose primary focus are children. Children' hospitalization often leads to parental anxiety as well as stress and sleep disorders. This condition can also trigger other pathologies such as hypertension, obesity, diabetes mellitus type II or stroke. Anxiety has higher rates on mothers of male infants. Conclusion: A long-term child's hospitalization brings an important and challenging parental adjustment affecting their health and wellbeing. Thereby, nurses' interventions should focus on identifying the adversities experienced by parents, so that actions can be taken that will improve the adaptation process, and consequently promote the parents' well-being in addition to their children's healing process. To this point, meeting family-centred care expectations is an additional paediatrics'
\end{abstract}


nurse challenge. Future studies on the strategies used by parents during their child's long-term hospitalization and its evaluation are needed.

\section{Keywords: long-term hospital stay; parents; anxiety; stress; sleep disorders}

\section{Introduction}

Parents have an important role on their children health care. While the focus of healthcare professionals is mostly the child; the financial, social and emotional impact on the child's parents is, often, overlooked. Considering that a child's hospitalization is, in most cases, unexpected, Melnyk (2000) affirmed that hospitalization could be a stressful situation for children and their parents/families, which may interfere with the care provided and thus with the recovery of the child.

As children's recovery depend, not only on the medical care, but also in the care and affection they may receive or not, it is crucial that nurses provide attention to the child, in addition to their technical expertise (Teixeira Luz et al., 2019).

Health care professionals must be sensitive to the parent's emotional needs as parents are an integrative component of the holistic care provided to the child. This is important as the parental presence and active participation during the child's hospitalization positively influences the health reestablishment due to stress reduction caused by the child's exposure to the hospital environment (Teixeira Luz et al., 2019). Yet, each family has different coping strategies, and it becomes extremely important for nurses to provide an individualized plan of care (Erdem, 2010), demonstrate empathy, compassion and kindness to engage with the children and their parents (Micalizzi et al., 2015), holistically.

A child's hospitalization may trigger parental stress, surface symptoms of anxiety and depression which will compromise their ability to give their child, proper support. (Nicholaou and Glazebrook, 2008). Given this, nurses should incite parents' ability to cope with these symptoms (Cescutti-Butler and Galvin, 2003). The partnership in care between parents and nurses allows, not only, for sharing of expertise, but it also provides an important sense of control from the parents over their child's hospital care as well as it builds a vital relationship of trust and confidence towards the healthcare team. (Mimmo et al., 2019).

Although the negative impact of long-term hospital admissions on parents are recognized, there is a dispersion of knowledge in the literature, which hampers the synthesis of best available evidence and thus its application into clinical practice. To achieve the proposed objective, the defined research question is: "What are the health problems experienced by parents of children in long-term hospitalization?" 


\section{Method}

The search was performed in March 2020, with the aim to identify health problems experienced by parents of children in long-term hospitalisations.

The review is a result of six phases: 1) guiding question definition; 2) literature search; 3) studies' categorization; 4) included studies' appraisal; 5) results interpretation and 6) synthesis. Research was carried out using the EBSCOhost search engine, selecting CINAHL Plus with Full Text and MEDLINE with Full Text as databases, with a timeline defined between 2015 and 2020, with the purpose of obtaining the most recent scientific evidence. The search was made in Portuguese and English and included the keywords "hospitalized children"; "parents"; "health problems" and the different synonymous of each keyword. Additionally, inclusion and exclusion criteria were defined. Thereby, only studies including parents of children of paediatric age (as per the study definition of paediatric age) in long-term hospitalisations were accepted for the review. Studies including parents who suffered from mental illness were excluded.

The search resulted in an initial sample of 149 scientific studies. Of these, 44 were excluded due to repetition, 87 based on title and abstract, resulting in a final sample of 18 articles. After full-text reading of the 18 studies, 13 were excluded for not meeting the inclusion/exclusion criteria. The final sample resulted on five studies that answered the investigation research question and met the inclusion criteria. (table 1 )

In order to establish the internal validity and mitigate the risk of bias during the selection process, the methodological quality of the studies was assessed using the Joanna Bridge Institute tools (JBI Reviewer's Manual, 2020).

Table 1: Identification of the included studies

Risk factors for the development of post-traumatic stress disorder and coping strategies in mothers and fathers Poland, 2017 following infant hospitalization in the neonatal intensive care unit. cancer in Lebanon.

Parents' experience of their sleep and rest when admitted to hospital with Sweden, 2018 their ill child: a qualitative study.

A4 Nassery W., Landgren K.

Early traumatic stress responses in par- 


\section{Results and discussion}

The type of studies included in this review are observational (A1), cross- sectional (A2 and $\mathrm{A}_{3}$ ), qualitative exploratory interview (A4) and a systematic review of the literature $\left(\mathrm{A}_{5}\right)$. All studies focused on parents of hospitalized children due to a variety of diseases, such as cancer, respiratory diseases, amongst others. Samples of the studies range from 17 to 460 parents. All the five studies present coping strategies used by parents of hospitalized children to deal with their struggles. Results were categorized and presented according to four different themes:

\section{Parental anxiety}

The A2 study highlights that the number of hospitalizations and the mother's anxiety had a negative impact in the caregiving performance while the mother-child relationship, if shown to be healthy, has a positive impact in the mother's caregiving performance. Also, this relationship, proved to positively impact the mother's anxiety. Melnyk (2000) corroborates these ideas stating that heightened anxiety often inhibits mothers from parenting their children effectively during hospitalization. Therefore, they are less likely to fulfill their protective, nurturing, and decision-making roles. In view of this, paediatric nurses need to plan interventions to minimize mother's anxiety and uncertainties regarding her child's illness, plan of care and prognosis, which should improve her effectiveness as a caregiver.

\section{Sleep quality}

The A4 study states that enough sleep is vital for parental functioning while they stay in the hospital with their children. As parents' priority is their child's well-being, they focus on the child, putting their own needs aside. Poor sleep makes parents more irritable with one another and understanding information and making healthcare decisions becomes challenging. Additionally, it is difficult to maintain a positive attitude and bright thought about the future, making the stay at the hospital more difficult to manage.

Environmental, interpersonal and organizational factors intervene in the quality of sleep. From the environmental perspective, parents reported that sounds from the hospital machines and noises of nurses during the night interfere with their sleep. Regarding interpersonal factors, parents who had relatives with whom they could share the child's care described it as an opportunity to catch up with their sleep. Accounting for the organizational factors, parents mentioned bureaucracy as an aspect that could develop stress and frustration even before time of admission. Løyland et al, (2020) validates these findings as they declare that the cohabiting with others, lack of privacy, noise and light when trying to sleep, disruptions due to treatments and child related and family factors affect parents' sleeping patterns. Sleep quality is also jeopardized 
when parents describe the shortage of healthcare providers as a potential risk for patient safety.

\section{Parental stress}

All three studies $\mathrm{A}_{1}, \mathrm{~A}_{3}$ and $\mathrm{A}_{5}$ reported high prevalence of parent's stress disorder. A1 states that mothers felt greater stress and presented a higher severity of post-traumatic stress disorder (PTSD) compared to fathers, especially if they had previous miscarriages or chronic diseases. Accounting for the fathers, the Apgar test after birth and partner's PTSD were related to PTSD. Similarly, findings of A5 study indicate that psychosocial factors, such as prior trauma, history of mental issues, trait anxiety and parent perception of life threat to their child, were consistently associated with parental acute and posttraumatic stress symptomatology. A study based on this theme carried out by Board and Ryan-Wenger (2002) adds that one of the most significant stressors for parents was the alteration in parental role. Interestingly, although the threat or salience of death may appear critical in the development of traumatic stress disorders in parents, many studies reported no association between objective medical characteristics (such as length of hospital stay, severity of illness, length of ventilatory support, and risk of mortality) and traumatic stress symptomatology in parents.

Study A1 reported that the differences in stress coping strategies among mothers and fathers are gender-related. Women used the following strategies more often than men: seeking emotional social support, religious coping, focusing on and venting emotions, positive reinterpretation, and growth (active coping) and acceptance (avoiding behaviour). Inside the group of parents mourning for their baby, women frequently coped with stress by focusing on emotions than the men. A study held by Tehrani et al, (2012) enhances that a higher level of family stress can reduce the ability of the mother to cope with problems. The occurrence of PTSD symptoms depends not so much upon the stressor but on how one copes with stress. Therefore, according to A3, maintaining family integration/strength and optimistic outlook for the situation was perceived as being the most helpful coping strategies. Tehrani et al. (2012) highlights the importance of understanding the differences related to stressors perception among nurses and parents, throughout a child's hospital stay. If not managed properly, strategies that aim at reducing parental stress may not be effective. Therefore, special attention should be given to identify the stressors in nursing care, planning and parents' education, moving stressors and treatment in the same direction, and identify factors that can reduce the mother's ability to provide childcare and delay in treatment progress. Also, information provision about a child's diagnosis was reported as a protective coping mechanism for parents and found to be associated with feelings of empowerment. 


\section{Interpersonal relationships}

A long-term hospital stay with an ill child has consequences on interpersonal relationships. According to the parents' interviews from A3 study, a long-term stay gives a feeling of unhappiness and isolation from the world outside the hospital. Callery (1997) declared the mothers' sense of isolation and the lack of support they were able to draw on from immediate family. Eyigor et al. (2011), states that the fear of the child's death, the length of the treatments, treatment-related drawbacks, distance from the caregiver's home to the hospital, financial problems, and negative effects on family relations tend to cause family psychosocial problems. Still, by being united as a family, parents felt stronger during their time of admittance. Spouses, relatives, and siblings served as a support system that help the parents as well as the ill child both practically and emotionally. Similarly, A2 shows that family support and positive emotional exchanges affect both the mother's and child's emotions. Also, a good parentchild relationship was associated with better outcomes related to the child's psychological functioning and family adaptation.

When considering coping strategies to deal with the hospitalization and the decay of relationships, a coping pattern in which parents maintain social activities and relationships, self-esteem, and psychological stability was found to have a significant protective role in parental a daptation to childhood disease, as shown by A3 study. The same coping pattern was found by the authors of A4 study, as all the participants described the importance of living their life as "normally" as possible including activities that reminded them that life had other meanings despite the child's disease, which was deemed as helpful to relax. Those having relatives and spouses bringing food so they could eat together, described that as creating a more home-like environment, which enabled the family functioning; however, since hospital wards only allow one parent during nighttime, the family members got separated which was described as difficult. Also the results of a study lead by Mason (1978) suggests that recurrently fathers are lead to believe, by the hospital's policy, that they are not supposed to be at the child's bedside and somehow blame themselves for not protecting the child. Fortunately, parents are becoming more aware of their rights, as well as of the value to the child of their visiting freely or rooming-in. The $\mathrm{A}_{3}$ study enhances that maintaining family integration/strength and optimistic outlook for the situation was perceived as being the most helpful coping strategy.

Parents at a hospital, inevitably connected with other parents and the medical staff. A4 study reveals that, even though all the parents wanted separate rooms, some of them mentioned positive aspects with having other families' sharing rooms, such as sharing the same experience and giving one another advice, becoming thereby significant partners in the treatment team, as reported by Mason (1978). By being on the "same boat", parents meant that their support and recommendations were invaluable. Also, talking with the health professional about concerns was among the top 10 most helpful cop- 
ing mechanisms to parents, as reported by the A3 study, which highlights the importance of providing understandable medical information to parents and children, upon their request. The A4 study states that relationships with nurses were described as very positive as they lessened the parental burden by providing practical support with the treatment of their child and decreased emotional stress by continuous information.

\section{Conclusion}

Parents who accompany their children during a long-term hospitalization may develop anxiety, stress and sleep pattern disorders and alterations in the interpersonal relationships. Although parents prioritize their child's best interests, the impact that the hospitalization can have on their health is highlighted as parents are aware of the deterioration of their health condition.

Being these in mind, nurses must adapt their interventions to minimize the impact of hospitalization effects. Negotiation may be the key to the success of the hospitalization, as it improves the quality of care for the hospitalized child. Clarification of the role of nurses and parents in the caring process is one of the prerequisites of this negotiation.

Throughout the evidence synthesis conducted, health units must develop clinical guidelines for interventions to promote parents' sleep and rest, as well as the implementation of effective educational programs to help mothers and fathers enhance their knowledge and skills and participation in the care, with the aim of optimizing their parenthood. Achieving greater psychological support and having as a basis of care the creation of a good working relationship and empathy, will establish parents a viable support for moments of greatest discouragement and stress.

There is already an accessible amount of studies related to some of the health problems experienced by parents of children in long term hospitalizations, with the great majority referring to parental stress and anxiety. Nevertheless, a greater scarcity when the main theme concerns sleep pattern disorders and alterations within the interpersonal relationships. Changes and disorders in terms of eating patterns should be a topic to be addressed with greater attention in future researches. Whilst there is already some research foundation on the theme, there is a need for a more in-depth and targeted search for physical, mental and social changes in parents of children going through long-term hospitalizations in order to identify risk groups, determining factors and strategies to support and solve the problems encountered by this research.

\section{References}

AFTYKA, A., RYBOJAD, B., ROSA, W., WRÓBEL, A. and KARAKUŁA-JUCHNOWICZ, H., 2017. Risk factors for the Development of Post-Traumatic Stress Disorder and Coping Strategies in Mothers and Fathers Following Infant Hospitalization in the Neonatal Intensive Care Unit. Journal of 
Clinical Nursing, no. 26, pp. 4436-4445. Available from: https://dx. doi. org/10.1111/jocn.13773

AROMATARIS E and MUNN Z., 2020. Joanna Briggs Institute Reviewer's Manual. Available from: https://reviewersmanual.joannabriggs.org/. https://dx.doi.org/10.46658/JBIRM-19-01

BEDELLS, E. and BEVAN, A., 2016. Roles of nurses and parents caring for hospitalized children. Nursing Children and Young People, vol. 28, no. 2, pp. 24-28. Available from: https:// dx.doi.org/ 10.7748/ncyp.28.2.24.s22

BOARD, R. and RYAN-WENGER, N., 2002. Long-term effects of pediatric intensive care unit hospitalization on families with young children. Heart \& Lung, vol. 31, no. 1, pp. 53-66. Available from: https:// dx.doi.org/ 10.1067/ mhl.2002.121246

CALLERY, P., 1997. Paying to participate: financial, social and personal costs to parents of involvement in their children's care in hospital. Journal of Advanced Nursing, no. 25, pp. 746-752. Available from: https://x.doi. org/10.1046/j.1365-2648.1997.to1-1-1997025746.x

CESCUTTI-BUTLER, L. and GALVIN, K. T., 2003. Parents' perceptions of staff competency in a neonatal intensive care unit. Journal of Clinical Nursing, vol. 12, no. 5, pp. 752-61.

ERDEM, Y., 2010. Anxiety levels of mothers whose infants have been cared for in unit level-I of a neonatal intensive care unit in Turkey. Journal of Clinical Nursing, vol. 19, no. 11-12, pp. 1738-1747. Available from: https:// dx.doi. org/ 10.1111/j.1365-2702.2009.03115.x

EYIGOR, S., KARAPOLAT, H., YESIL, H., and KANTAR, M., 2011. The quality of life and psychological status of mothers of hospitalized pediatric oncology patients. Pediatric hematology and oncology, vol. 28, no. 5, pp. 428-438. Available from: https://dx. doi.org/10.3109/08880018.2011.574202

HYE-YUL, H., SHIN-JEONG, K., WAYNE, E. K. and KYUNG-AH, K., 2018. Factors influencing the caregiving performance of mothers of hospitalized toddlers with acute respiratory diseases: A path analysis. Journal of Child Health Care, vol. 22, no. 4, pp. 591-605. Available from: https:// dx. doi.org/10.1177/1367493518767064

LAKKIS, N. A., KHOURY, J. M., MAHMASSANI, D. M., RAMIA, M. S. and HAMADEH, G. N., 2016. Psychological distress and coping strategies in parents of children with cancer in Lebanon. Psycho-Oncology, vol. 25, no. 4, pp. 428-434. Available from: https:// dx.doi.org/10.1002/pon.3934

LAPILLONNE, A., REGNAULT, A., GOURNAY, V., GOUYON, J., GILET, H., ANGHELESCU, D., MILORADOVICH, T., ARNOULD, B. and MORIETTE, G., 2012. Impact on parents of bronchiolitis hospitalization of fullterm, preterm and congenital heart disease infants. BMC Pediatrics, vol. 12, no. 171. Available from: https://dx.doi.org/10.1186/1471-2431-12-171 
LØYLAND, B., ANGELHOFF, C., KRISTJÁNSDÓTTIR, G. and SJØLIE, H., 2020. A systematic integrative review of parents' experience and perception of sleep when they stay overnight in the hospital together with their sick children. Journal of Clinical Nursing, no. 29, pp. 706-719. Available from: https://dx.doi.org/10.1111/jocn.15134

MASON, E. A., 1978. Hospital and Family Cooperating to Reduce Psychological Trauma Community Mental Health Journal, vol. 14, no. 2.

MELNYK, B. M., 200o. Intervention Studies Involving Parents of Hospitalized Young Children: An Analysis of the Past and Future Recommendations. Journal of Pediatric Nursing, vol. 15, no. 1, pp. 4-13. Available from: https:// dx.doi.org/ 10.1053/jpdn.2000.0150004

MICALIZZI, D., DAHLBORG, T. and ZHU, H., 2015. Partnering with parents and families to provide safer care: seeing and achieving safer care through the lens of patients and families. Current Treatment Options in Pediatrics, vol. 1, no. 4, pp. 298-308. Available from: https:// dx.doi.org/10.1007/ S40746-015-0034-4

MIMMO, L., WOOLFENDEN, S., TRAVAGLIA, J. and HARRISON, R., 2019. Partnerships for safe care: A meta-narrative of the experience for the parent of a child with Intellectual Disability in hospital. Health Expectations, vol. 22, no. 6, pp. 1199-1212. Available from: https:// dx.doi.org/10.1111/ hex.12968

NASSERY, W. and LANDGREN, K., 2018: Parents' Experience of Their Sleep and Rest When Admitted to Hospital with Their Ill Child: A Qualitative Study. Comprehensive Child and Adolescent Nursing, vol. 42, no. 4, pp. 265-279, Available from: https://dx.doi.org/10.108o/24694193.2018.1528310

NICHOLAOU, M. and GLAZEBROOK, C., 2008. Emotional support for families of sick neonates. Paediatrics and Child Health, vol. 18, no. 4, pp. 196199.

TEHRANI, T, HAGHIGHI, M. and BAZMAMOUN, H., 2012. Effects of Stress on Mothers of Hospitalized Children in a Hospital in Iran. Iran Journal of Child Neurology, vol. 6, no. 4, pp. 39-45.

TEIXEIRA LUZ, R., SILVA TRINDADE, T. B., DE SOUZA LIMA, D., CARDOSO CLIMACO, L. C., SANTOS FERRAZ, I., RIBEIRO TEIXEIRA, S. C. and RODRIGUES DA SILVA, R., 2019. The Importance of the Presence of Parents during Neonatal Hospitalization. Journal of Nursing UFPE, no. 13, pp. 414-419.

WOOlF, C., MUSCARA, F., ANDERSON, V. A. and MCCARTHY, M. C., 2015. Early Traumatic Stress Responses in Parents Following a Serious Illness in Their Child: A Systematic Review. Journal of Clinical Psychology in Medical Settings, vol. 23, no. 1, pp. 53-66. Available from: https:// dx.doi.org/10.1007/s10880-015-9430-y 